\title{
Concept Inventories as Predictors of Changing Pre-Engineering Skills
}

\section{Dr. Shelley Lorimer P.Eng., MacEwan University}

Shelley Lorimer is the Chair of the Bachelor of Science in Engineering (BSEN) Transfer Program at Grant MacEwan University. She is an instructor in the introductory engineering courses as well. The BSEN program at MacEwan has grown from forty students since in started almost fifteen years ago, to the current 216 students. The majority of the students in the program transfer to second year engineering at the University of Alberta.

Shelley is a graduate of the University of Alberta in engineering and is a registered professional engineer with APEGA (Association of Professional Engineers and Geoscientists of Alberta). Prior to her career at MacEwan, Shelley worked in industry as a research engineer and a consulting engineer for several years. 


\title{
Assessment Tools as Predictors of Changing Pre-Engineering Skills
}

\begin{abstract}
$\underline{\text { Abstract }}$
This article was motivated by a need to understand the academic strengths and weaknesses of engineering students entering first-year. The underlying impetus was the improvement of the educational process. At our institution, and perhaps in general, there is an anecdotal hypothesis that the mathematical skills, or more generally, the academic strengths of first-year engineering students have been significantly declining in the last two decades. To address this hypothesis, a longitudinal study of pre-engineering indicators for first year engineering students in a Canadian university transfer program was initiated almost a decade ago through the use of two assessment exams and by collection and consolidation of high school achievement data. It is not unusual to use these academic indicators as a measure of skill level. To this end, two assessment tools (Math Advisory and Engineering Assessment) were used to generate data with which to test this hypothesis. Simple statistical analyses and temporal trend plots were used to examine the data.

The results of the data analysis gave rise to some interesting observations. The Math Advisory exam mean scores for engineering students considered in this study were consistently between 50-55\% during the period considered, with little variation from year to year. The same trend was observed for the Engineering Assessment mean scores (Force Concept Inventory). In both cases, the changes in the mean scores over time were analyzed using a $t$-test, and the analysis indicated that the changes in the mean scores were not statistically significant. Overall high school achievement of these students entering first-year also showed little variation during this same time period. Comparison of the assessment exam mean scores to high school achievement data showed that performance on assessment exams was much poorer than high school achievement might have predicted. There was $\sim 30 \%$ reduction in performance when the assessment indicators were compared to high school achievement.
\end{abstract}

As a result of the overall poor performance on the assessment exams (50-55\%), as well as inconsistency between results on the Math Advisory exam and high school achievement in math, the engineering program has regularly implemented weekly math and engineering tutorial sessions to supplement the course curricula. However, at this stage the success of these initiatives has not been verified. Although the data at first glance (10.89 compared to 10.6 for Math Advisory exam) might indicate a decline in the performance of engineering students on the math assessment exam, the data does not support the anecdotal hypothesis nor the quantitative evidence of markedly declining math skills in first-year engineering students at our institution, at least during the time period considered.

Assessment tools are often used in a predictive way to gauge the overall skills of engineering students. They are also useful in setting engineering program directives. It is clear from this article that the academic averages obtained in high school, may not necessarily reflect the skill level of the students entering first-year, especially in mathematics. A further analysis of these assessment results in light of first-year academic achievement might reveal further information regarding the success or lack thereof in delivering the first year curriculum. 


\section{$\underline{\text { Introduction }}$}

The purpose of this research was to examine trends in academic indicators for first-year engineering students entering an engineering transfer program at a Canadian university. Three academic indicators were used: mean scores from two assessment exams and mean averages from high school admissions data. These indicators were examined over a ten year period to determine whether or not there was a statistically significant change. ${ }^{*}$ Specifically, the original intent was to confirm evidence provided in the literature regarding the declining math and science literacy of engineering students entering universities, since quantitative studies in the UK and US had supported this hypothesis. Davis et al. ${ }^{1}$ cited reports affirming the extent of the "mathematics problem" in the UK, while several other authors alluded to the similar issues in the $\mathrm{US}^{2-7}$

In this study, mathematical skills for the period 2000-2011 were tested using a 20-question, multiple-choice, pre-calculus Math Advisory exam, administered to first-year engineering students (without calculators) prior to entering first-year. Engineering skills were evaluated during the period 2007- 2011 using the Force Concept Inventory (FCI) Exam, which is a 30question, multiple-choice exam ${ }^{8}$. This research seeks to address the anecdotal hypothesis that the pre-engineering skills of engineering students at our institution are significantly declining.

As a result of the exploration of this hypothesis, additional observations were made during the analysis of the data and as a result of the literature review. It became evident from a review of methods of assessment of pre-engineering skills, that other institutions in the US use the Force Concept Inventory to assess first year engineering students, in both a pre- and post-test fashion. The results obtained in this study were compared to those results. In addition, it seemed natural to compare all of the assessment results to the overall high school admissions averages of the students to see if the results on these two assessment exams were reflective of the of their high school grades. A comparison of the FCI results from other institutions in the U.S. confirmed that the performance of the students in this study on the Force Concept Inventory exam was quite similar to that of their US counterparts.

\section{Background}

There is substantial literature on the use of assessment tools and analysis of the data generated from these types of assessment, particularly as it applies to engineering education. In the context of this paper, math assessment/placement exams and concept inventories are considered to be indicators of skill and/or aptitudes, whether they be chemistry, physics or mathematics. Hake has provided a survey of much of the research that has been done using the Force Concept Inventory up until 1998. This research has used FCI as an engineering assessment tool.

Many researchers have conducted longitudinal studies of undergraduate engineering students in an attempt to understand how to provide the best possible engineering education. Web pages have been devoted to the distribution of physics/engineering assessment exams ${ }^{10}$ (used to examine students' understanding of basic force and mechanics concepts), while surveying the results of these assessment exams to glean some new facet of information that might address the

\footnotetext{
${ }^{*}$ Data for the engineering assessment exam was only available for 2007-2011.
} 
gap that exists between the students' readiness to succeed in engineering and the fulfillment of the expectations of earning an engineering degree. However, the literature survey done in this study did not reveal specific data, which gave quantitative evidence supporting declining skills in mathematics.

Other educators have demonstrated the need for "understanding our students”. Bernold et al. ${ }^{11}$ have written a comprehensive summary about success and failure in engineering and the factors that contribute to it. The conclusion that they reached is that engineering educators need to take a "learner-centered" approach to engineering education, where they must pay "careful attention to the knowledge, skills, attitudes, and beliefs that the learners bring to the educational setting". Clearly, we must understand if and how the pre-engineering skills are changing and perhaps try to quantitatively identify some of the key indicators that affect success and failure, to address the educational needs of the students.

A consistent theme in the literature is the "mathematics problem" which has been identified by numerous researchers in the US and UK. Adamcyk et al. ${ }^{2}$ acknowledged, as late as 2002, the "anecdotal nature" of evidence of math deficiencies in engineering students in the US, and at that time undertook a study to assess the math proficiency of students at Grand Valley State University in Michigan. They observed that students lacked problem solving proficiency. The paper also indicated that algebra is the domain of K-12 schools (presumably in the US), while calculus is the domain of higher education institutions. This is not the case for the engineering students considered in our study, who have both algebra and calculus when they are admitted to first-year.

The literature review provided by Moses et $\mathrm{al}^{7}$, in their study of math readiness, confirmed the importance of entering math skill on retention in engineering. Furthermore, their study indicated that students who took advanced math courses in high school were more likely to be successful in college. Although their study did not speak to the issue of math deficiencies per se, they did find that calculus readiness and high school GPA were predictive of retention. Assessment instruments (tools) were used in their research to provide data for analysis to examine hypotheses for retention in a first-year engineering program.

The "lack of preparation of students", in general, is another common theme in the literature of research done in engineering education, and the literature indicates that this problem is quite widespread. In particular, McFate and Olmstead ${ }^{12}$ have identified this issue in Chemistry courses at California State University. They indicated success rates in Chemistry at their institution may be only $65-70 \%$ in first year courses. Their article proposes remediation and preparatory instruction and the use of placement tests. Their article cited research that established a correlation between mathematics aptitude and success in general chemistry. This information is quite pertinent to engineering education at our institution, since first-year chemistry is a part of the first-year engineering curriculum. The "mathematics problem" identified earlier might be considered to be a subset of the more general lack of preparation or readiness of students.

To date in the literature there are many studies that have been done to identify the "formula" for "successfully" educating engineering students. Due to the complexity of factors that influence success and retention in engineering, no definitive answer for success has been identified. 
Furthermore, there does not appear to be any literature devoted to a comparison of academic success in engineering and success as an engineer after graduation.

The most comprehensive analysis obtained from the literature review is presented by Veenstra et al. ${ }^{13}$ Predictors of academic success for engineering students included: high school GPA or rank and SAT math and/or math and chemistry placement exams.

It seems that a natural extension to the role of an engineering educator is to seek understanding of the educational process through the analysis of data. It is this desire for understanding, from an engineering program perspective, that this research was done: to gain a better understanding of the skills that engineering students possess upon entering the engineering program. There are several initiatives that seek to use results of this type to improve first year instruction, and thereby decrease attrition from science based courses. It is the continued quest for this knowledge that has motivated this article. This initiative speaks to many of the concerns that have been addressed in and summarized in the background provided in this section.

\section{Data}

The data for this study was collected through the engineering program at Grant MacEwan University which is a small university in Edmonton, Alberta, Canada. Throughout the course of the study, the sample of students varied from 112 to 163 as the program expanded during that time period. It should be noted that not all of the students that were admitted to the program participated in the study due to the way in which the assessment exams were administered. Our program currently has an admission quota of 216 . There was tremendous change in the program throughout this study as a result of this growth. A huge variability in instruction occurred but more importantly it was anticipated that increasing enrolment, while drawing from the same admissions pool, might affect the quality of the students entering the program. The admission requirements $^{\dagger}$ were not changed during this time, however, it was expected that the expansion would result in taking more students with lower high school achievement. ${ }^{\ddagger}$ Since high school achievement is predictive of success in engineering, this was deemed to be problematic from both the program and student perspective. The data presented later will show that this situation did not occur. The demand for engineering mitigated this potential problem.

The data for the first year engineering students considered in this study are presented in Table 1 for the Math Advisory exam and Table 2 for the Engineering Assessment exam (Force Concept Inventory FCI) for the years indicated. In each case, the number of students, the mean score and $\%$ score of the students on the assessment exams for each year are presented. The visual representation of these two data sets is presented in Figure 1.

\footnotetext{
† Students admitted to engineering must have Math 30-1, Math 31, Physics 30, Chemistry 30, and English 30-1

$\ddagger$ The cutoff average at our institution is $75 \%$.
} 


\begin{tabular}{|c|c|c|c|}
\hline \multicolumn{4}{|c|}{ Table 1 -Mean Scores for First Year Engineering Students in Math Advisory Exams } \\
\hline \hline Year & Number of Students & Mean /20 & \% Score \\
\hline 2000 & 112 & 10.89 & 54 \\
\hline 2001 & 110 & 10.98 & 55 \\
\hline 2002 & 109 & 10.07 & 50 \\
\hline 2003 & 115 & 10.79 & 54 \\
\hline 2004 & 109 & 10.48 & 52 \\
\hline 2005 & 116 & 11.16 & 56 \\
\hline 2006 & 115 & 10.52 & 53 \\
\hline 2007 & 117 & 12.16 & 61 \\
\hline 2008 & 137 & 10.13 & 51 \\
\hline 2009 & 194 & 10.52 & 53 \\
\hline 2010 & 185 & 10.42 & 52 \\
\hline 2011 & 163 & 10.60 & 53 \\
\hline
\end{tabular}

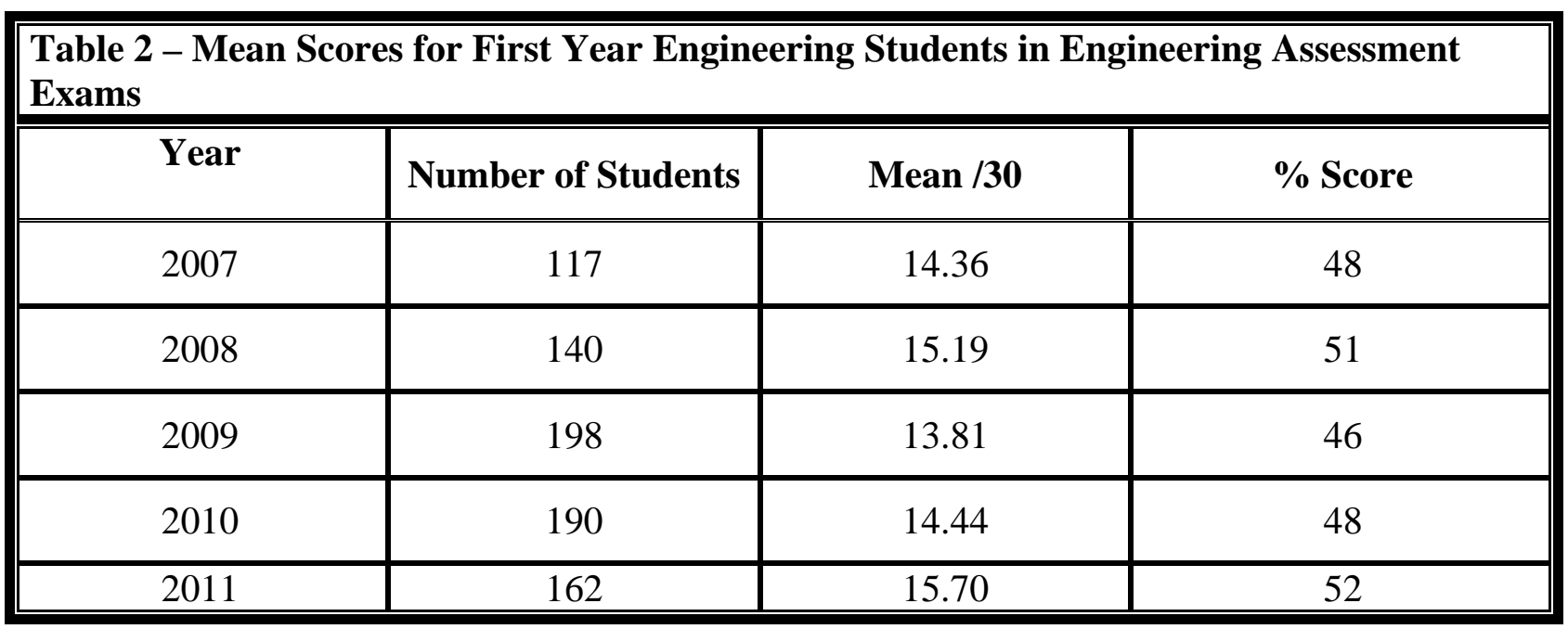

The results in Figure 1 demonstrate visually that there is not a large temporal variability in the mean scores for these two exams. Although the mean score for the Math Advisory exam in 2011 is smaller than the mean score in 2000, there is not an obvious decline in the data. There is somewhat more variation in the mean Math Advisory scores, than the high school averages, which are almost constant at $\sim 80 \%$. A student $t$-test was used to examine the data in a more rigorous fashion.

To test the hypothesis that the average on the Math Advisory exam did not decline between 2000 and 2011, the following hypotheses were tested at a significance level of 0.05:

$\mathrm{H}_{0}: \mu_{2011} \geq \mu_{2000}:$ null hypothesis

$\mathrm{H}_{1}: \mu_{2011}<\mu_{2000}$ : alternative hypothesis

where $\mu$ represents the mean of the sample at a given time. 
A $t$-test ${ }^{14}$ was used to examine these hypotheses resulting in a $t=0.68$, degrees of freedom $=235$ and with a $p$ value of 0.25 . There is no evidence, using this data that the mean score on the Math Advisory exam declined between 2000 and 2011. A visual examination of the data in Figure 1 confirms this, since there is no observable decline in the mean percentage scores of the students during the period 2000-2011.

The same analysis was conducted on the Engineering Assessment (FCI Inventory) data. The following hypotheses were tested, again, using a significance level of 0.05 .

$\mathrm{H}_{0}: \mu_{2011} \geq \mu_{2007}:$ null hypothesis

$\mathrm{H}_{1}: \mu_{2011}<\mu_{2007}$ : alternative hypothesis

A $t$-test was used to examine the hypotheses resulting in a $t=-1.75$, degrees of freedom $=243$ and with a $p$ of 0.95 . The same conclusion was reached: there is no evidence that a statistically significant decrease in the scores on the Engineering Assessment exam occurred between 2007 and 2011. The Engineering Assessment data can also be compared to results from another completely independent source, obtained by Docktor and Heller ${ }^{15}$, who published FCI scores for over 5000 science and engineering students at the University of Minnesota taken between 1997 and 2007. Their overall results indicated that the average mean score on the FCI Inventory assessment exam was $\sim 50 \%$. Their results also showed an increasing trend in FCI pre-test scores with time, but the analysis did not indicate whether or not this increase was statistically significant. The overall weighted average score for all students in this study was $\sim 49 \%$, but there does not appear to be an increasing trend in the data considered this study. It is quite interesting to note that the scores on the FCI for students in this study (on average) are similar to those of engineering/science students at the University of Minnesota, considering that many factors that would influence these scores would be different (geography, educational background, admission requirements etc.)

The admissions data (mean high school averages) for the students considered in this study are presented in Table 3. The mean overall averages for the various years are highlighted in red. The mean averages in the five high school courses required for admission are also summarized in the table. The mean overall admission averages are plotted in Figure 1 to illustrate the comparison to assessment exam score data. The small fluctuations in the data for the different indicators do not appear to correlate with one another. There seem to be more fluctuations in the math scores than the high school averages. It is interesting that the scores on both the Math Advisory exam and the Engineering Assessment exam are $~ 30 \%$ below the mean overall admissions averages. They are also $\sim 30 \%$ below the mean averages in the physics and math courses as well. If high school achievement is reflective of students' abilities/skills, it would seem that either the high school averages are inflated or the expectations of the assessment exams are too high. The students in this study were generally disappointed and concerned about their scores on these exams, even though the results from these exams were not included in their first year evaluations.

Assessment exams are merely used to gauge the areas where the students are weak, rather than as a placement tool. However, this information was used to establish the use of tutorials and remedial sessions as a part of the program at our institution. 
The Engineering Assessment exam was also used in a pre- and post-test manner for one year only: 2010. These results are presented in Table 4. The pre-test was given before classes began, and the post-test was given at the end of the first year. The average post-test score increased by $11 \%$. Similar results published by Docktor and Heller ${ }^{15}$ showed an increase of $20 \%$ between the pre- and post-test results on the same FCI exam. The method of instruction in the classes that were tested in their study emphasized a problem solving approach. The method of instruction for the students considered in this analysis was more a traditional, lecture style format. The literature seems to indicate that these assessment scores can be improved by changing the format of course instruction. This is an initiative that is worth exploring. Continued research in this area would be beneficial particularly in light of the amount of data that has already been collected in this program.

\section{$\underline{\text { Discussion }}$}

Even though the original hypothesis of declining math skills was not quantitatively supported by this study, it became clear during the detailed examination of the data, that the math skills that students have entering our institution are not consistent with their high school math achievement scores. This inconsistency is sometimes referred to as grade inflation. Govender et al. ${ }^{16}$ observed grade inflation in a study done in South Africa comparing National Senior Certificate (NSC) math scores to the pass rate of first-year engineering physics. It was observed that math marks were not matched by actual performance. Grade inflation may have a substantial impact on success and retention in engineering, especially high school grade inflation which has been identified as a predictor of engineering success. Much like other institutions in the US and UK, the South African students were in need of remedial programs to help address this problem. This study, along with previous studies cited in this article, demonstrates that the concern regarding weakness in math skills is widespread in engineering educational communities (US, UK and South Africa).

A more interesting result of our study is that the indicators did not vary significantly during a ten-year time period. A possible explanation of this might be due to our admissions criteria. Two math courses (Math 30 - algebra and Math 31 - calculus) are required for admission to our engineering program, hence our students take an "advanced” math course compared to their US counterparts, where calculus is the domain of higher education rather than K-12. So, far these math requirements have not been relaxed, and certainly were unchanged throughout this study.

Moreover, if the indicators used in this study are also predictors of success in engineering, one might expect that the success rate of students in this study might be relatively constant as well. At this stage, it certainly begs the question to examine the GPAs of these students to see if this trend is observed. One might expect that in the future if these indicators change, it could be indicative of substantial changes in the K-12 curriculum or some other contributing factor the students experience prior to enrolment in first-year engineering. This longitudinal study may also provide a foundation for assessing the success or failure of initiatives that are being undertaken or those that may be proposed in the future to improve the success and retention of first-year engineering students at our institution. 


\begin{tabular}{|c|c|c|c|c|c|c|c|c|c|c|c|c|c|}
\hline Year & 1999 & 2000 & 2001 & 2002 & 2003 & 2004 & 2005 & 2006 & 2007 & 2008 & 2009 & 2010 & 2011 \\
\hline \multicolumn{14}{|l|}{ Category } \\
\hline $\begin{array}{l}\text { Number of } \\
\text { Students }\end{array}$ & 109 & 113 & 116 & 119 & 120 & 123 & 122 & 120 & 120 & 142 & 212 & 212 & 197 \\
\hline $\begin{array}{c}\text { Overall Admission } \\
\text { Ave.* }\end{array}$ & 77.0 & 76.9 & 77.6 & 76.7 & 79.5 & 78.6 & 79.7 & 79.5 & 81.1 & 80.6 & 79.3 & 79.0 & |79.3 \\
\hline \multirow{3}{*}{\begin{tabular}{|c||} 
Science Average: \\
Physics \\
Average:
\end{tabular}} & $\begin{array}{l}66- \\
93 \\
\end{array}$ & $\begin{array}{r}65- \\
89 \\
\end{array}$ & $\begin{array}{l}70- \\
92 \\
\end{array}$ & $\begin{array}{c}66- \\
90 \\
\end{array}$ & $\begin{array}{c}67- \\
95 \\
\end{array}$ & $\begin{array}{c}65- \\
95 \\
\end{array}$ & $\begin{array}{l}70- \\
92 \\
\end{array}$ & $\begin{array}{l}70- \\
97 \\
\end{array}$ & $\begin{array}{l}71- \\
93 \\
\end{array}$ & $\begin{array}{c}75- \\
93 \\
\end{array}$ & $\begin{array}{c}67 .- \\
96 \\
\end{array}$ & $\begin{array}{c}71- \\
92 \\
\end{array}$ & $\begin{array}{c}70- \\
92 \\
\end{array}$ \\
\hline & 79.0 & 78.4 & 79.3 & 78.4 & 81.1 & 80.4 & 82.0 & 80.9 & 83.1 & 82.6 & 81.2 & 81.1 & 81.2 \\
\hline & 78.0 & 77.6 & 78.7 & 78.4 & 80.9 & 79.9 & 81.0 & 79.7 & 82.1 & 78.9 & 78.8 & 78.1 & 79.0 \\
\hline $\begin{array}{l}\text { Math } 30 \\
\text { Average: }\end{array}$ & 80.9 & 80.8 & 80.7 & 80.1 & 83.0 & 82.0 & 84.0 & 82.9 & 83.1 & 81.1 & 83.0 & 83.1 & 82.0 \\
\hline $\begin{array}{l}\text { Math } 31 \\
\text { Average: }\end{array}$ & $\mid 78.7$ & 77.6 & 79.3 & 77.6 & 81.0 & 80.0 & 81.0 & 80.0 & 83.1 & 82.1 & 82.6 & 81.7 & 83.0 \\
\hline $\begin{array}{l}\text { Chem } 30 \\
\text { Average: }\end{array}$ & 78.0 & 77.0 & 78.0 & 77.0 & 80.0 & 79.0 & 82.0 & 81.0 & 84.3 & 80.0 & 80.4 & 81.4 & 80.0 \\
\hline $\begin{array}{c}\text { English } 30 \\
\text { Average: }\end{array}$ & 68 & 70 & 70 & 69 & 73 & 72 & 71 & 73 & 72 & 72 & 68 & 71 & 72 \\
\hline $\begin{array}{c}\text { English } 30 \\
\text { Range: }\end{array}$ & $\begin{array}{c}50- \\
89\end{array}$ & $\begin{array}{c}50- \\
90 \\
\end{array}$ & $\begin{array}{c}52- \\
90 \\
\end{array}$ & $\begin{array}{c}50- \\
92 \\
\end{array}$ & $\begin{array}{c}50- \\
96\end{array}$ & $\begin{array}{c}50- \\
95 \\
\end{array}$ & $\begin{array}{c}53- \\
94 \\
\end{array}$ & $\begin{array}{c}50- \\
92 \\
\end{array}$ & $\begin{array}{l}50- \\
92 \\
\end{array}$ & $\begin{array}{c}54- \\
93\end{array}$ & $\begin{array}{c}52- \\
99 \\
\end{array}$ & $\begin{array}{c}52- \\
91 \\
\end{array}$ & $\begin{array}{l}51- \\
94\end{array}$ \\
\hline
\end{tabular}

Table 4 -Engineering Assessment Scores for First Year Engineering Students (2010)

\begin{tabular}{|c|c|c|c|}
\hline \hline Year & Number of Students & Mean /30 & \% Score \\
\hline \hline 2010 Pre-Test & 162 & 15.70 & 52 \\
\hline 2010 Post-Test & 163 & 18.75 & 63 \\
\hline
\end{tabular}




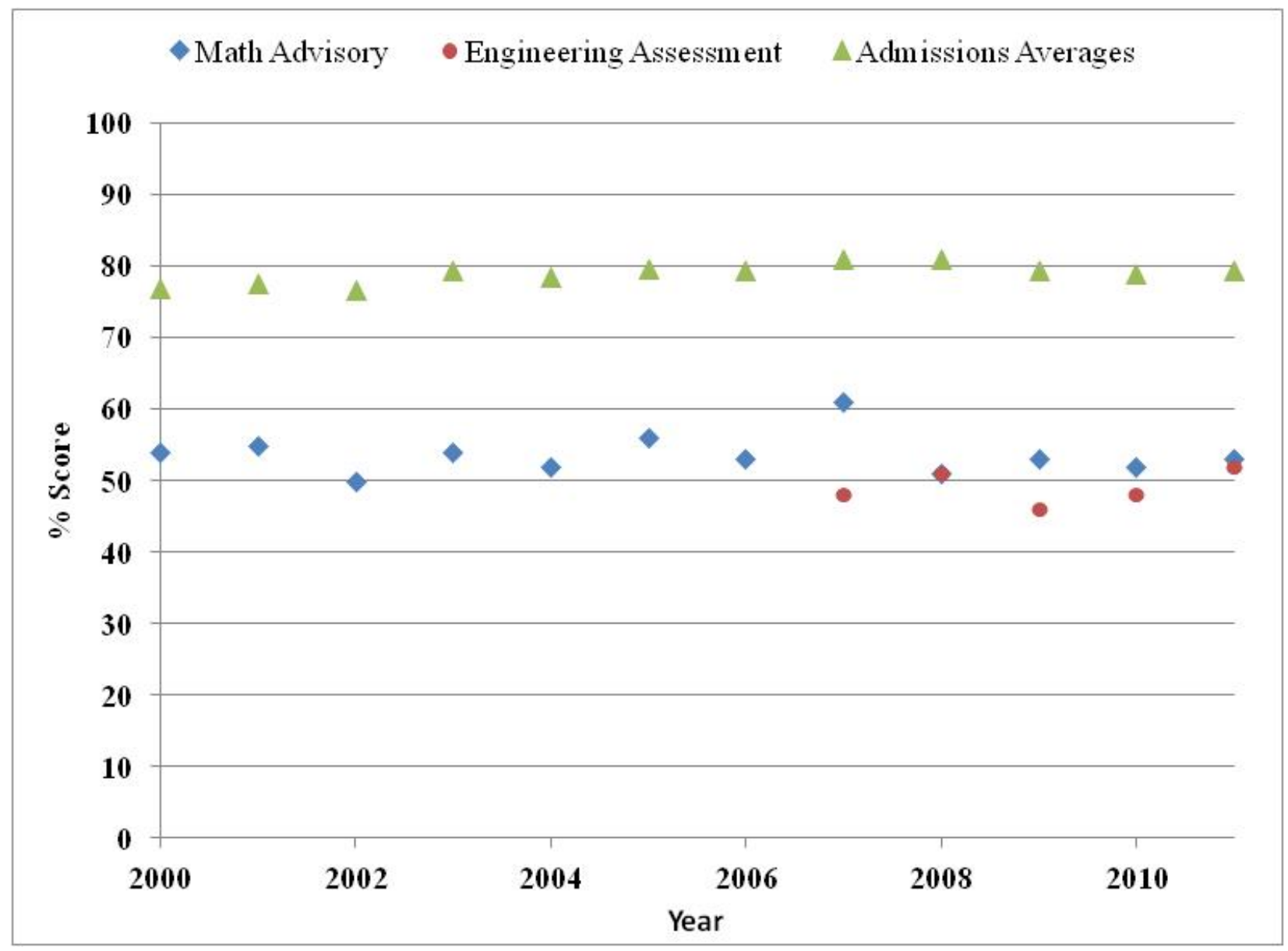

Figure 1: Math Advisory \& Engineering Assessment exam scores \& Admissions Averages for 2000 - 2011

\section{Summary}

Analysis of the data obtained from a decade of pre-engineering assessment scores does not confirm the anecdotal hypothesis that our engineering students' pre-engineering skills are declining. However, it does seem to demonstrate math deficiencies through the low mean scores on the Math Advisory exam. It is possible that assessment exam scores may not be reflective of the students' capabilities and/or skills, but whatever qualities are measured using these assessment tools have not changed, at least in an average sense. It is clear from the data that the scores on these assessment tools, much like the admissions averages for these students, have been relatively constant over the time period considered. It is also clear, that the performance of these students on the FCI is similar to students at the University of Minnesota in both magnitude and variability. Further exploration is needed to determine whether or not the scores on these assessment exams can be influenced by a change in teaching methods, and whether or not a change in these scores would be meaningful. A more detailed analysis of the data may provide insight into some of the "perceived” skill deficiencies of engineering students. 


\section{Bibliography}

1. Davis, L. E., M. C. Harrison, A. S. Palipana, and J. P. Ward. "Assessment-Driven Learning of Mathematics for Engineering Students." International Journal of Electrical Engineering Education 42, no. 1 (01, 2005): 63-72.

2. Adamczyk, B., W. Reffeor, and H. Jack. "Math Literacy and Proficiency in Engineering Students." ASEE Annual Conference Proceedings, 2002.

3. Skokan, C. and P. Rodriguez. "Assessment of a Coordinated Effort to Increase Student Learning in Mathematics and Science through Engineering Examples." ASEE Annual Conference Proceedings, 2006.

4. Carpenter, J. and R. E. Hanna. "Predicting Student Success in Calculus." ASEE Annual Conference Proceedings, 2007.

5. Bochis, C., Hsia, S. Johnson, P. Boykin, K. Wood, S., Bowen L., and K. Whitaker. "Integrated Engineering Math-Based Summer Bridge Program for Student Retention." ASEE Annual Conference Proceedings, 2007.

6. Steele, N. "Engineering Mathematics--Dare to Hope?" Teaching Mathematics \& its Applications 22, no. 4 (12, 2003): 199-208.

7. Moses, L., Hall, C.,Wuensch K., De Urquidi K., Kauffmann P., Swart W., Duncan S., and G. Dixon. "Are Math Readiness and Personality Predictive of First-Year Retention in Engineering?" Journal of Psychology 145, no. 3 (05, 2011): 229. doi:10.1080/00223980.2011.557749.

8. Hestenes, D. , Wells, M. and Swakhamer. "Force Concept Inventory", The Physics Teacher, Vol. 30, March 1992, 141-158.

9. R.R. Hake, "Interactive-Engagement vs Traditional Methods: A six-thousand-student survey of mechanics test data for introductory physics courses", Am. J. Phys. 66, 1998, p.64- 74.

10. Force Concept Inventory. 9 Oct. 2010. Modeling Instruction Program. Arizona State University. 1 March 2011 < http://modeling.la.asu.edu/R\&E/Research.html>

11. Bernold, J.E., Spurlin, J.E., and C.M Anson. "Understanding Our Students: A Longitudinal Study of Success and Failure in Engineering with Implications for Increased Retention", Journal of Engineering Education, 96 No. 3, July 2007, 263-274.

12. McFate, C. and J. Olmsted III. "Assessing Student Preparation through Placement Tests." Journal of Chemical Education 76, no. 2-4 (1999): 562-565.

13. Veenstra, C. P., Dey, E., and G. Herrin. "Is Modeling of Freshman Engineering Success Different from Modeling of Non-Engineering Success?" Journal of Engineering Education 97, no. 4 (10, 2008): 467-479.

14. Berenson, M. and D. Levine. "Basic Business Statistics: Concepts and Applications", 6th Edition, Prentice Hall, NJ, 1996.

15. Doctor, J. and K. Heller. "Gender Differences in Both Force Concept Inventory and Introductory Physics Performance" , Physics Education Research Conference 2008, Edmonton, Alberta, July, 2008, 15-18.

16. Govender, J. and M. Mervlyn. "Effect of National Senior Certificate Maths on the Pass Rate of First-Year Engineering Physics." South African Journal of Science 108, no. 7 (Jul, 2012): 1-5. doi:10.4102/sajs.v108i7/8.830. 